\title{
Corrosion of Aluminum Alloy 2024 Caused by Aspergillus niger
}

Xinyan Dai, Hua Wang, Lu-Kwang Ju, Gang Cheng, Hongbo Cong, Bi-min Zhang Newby* Department of Chemical and Biomolecular Engineering

The University of Akron

Akron, OH 44325-3906, USA

* Corresponding author

Bi-min Zhang Newby

Professor

Department of Chemical and Biomolecular Engineering

The University of Akron, Akron, $\mathrm{OH} 44325-3906$

Phone: +1 (330) 9722510

E-mail: bimin@uakron.edu (B.-m. Zhang Newby) 
Abstract:

Corrosion of aluminum alloy 2024 (AA 2024-T3) exposed to fungus Aspergillus niger cultured on glucose containing potato dextrose agar was studied in a high humidity and sterile atmospheric environment. The biofilm evaluation, weight loss measurement, quantitative pit analysis and corrosion product characterization were carried out. Results showed that, under this condition, the presence of $A$. niger accelerated corrosion process. The corrosion rate of AA 2024-T3 by A. niger was more than 4 times of that exposed to $\mathrm{NaCl}$. Also, severe pitting corrosion, comparable to AA 2024-T3 exposed to $\mathrm{NaCl}$, and aluminum depletion accompanied with copper enrichment were observed. Furthermore, the corrosion morphology was found to be related to the biofilm thickness. The dominant metabolite of $A$. niger under our experimental condition was identified to be oxalic acid, an aggressive corrodent that causes similar corrosion rate and corroded pit morphology as those observed in in this study. Therefore, oxalic acid produced by $A$. niger under our specific experimental condition is believe to be the main cause for the corrosion of AA 2024-T3.

Keywords: aluminum alloy; microbiologically influenced corrosion; weight loss; surface roughness

\section{Introduction}

The annual costs of corrosion are in trillions and account $~ 6 \%$ of the Gross World Product (Jackson, 2013). Microbiologically influenced corrosion (MIC) is due to the result of the presence or activities of microorganisms such as, but not limited to, bacteria, microalgae, lichens and fungi (Little et al., 2007). MIC could pose serious concerns in industries including water distribution systems (Teng et al., 2008), underground storage tanks (Sowards and Mansfield, 2014a), and oil storage, transportation (Rajasekar and Ting, 2010; Giacobone et al., 2011; AlAbbas et al., 2013; Sowards et al., 2014b), and nuclear waste storage facilities (Giacobone et al., 2011).

A great deal of research has been dedicated to the causative bacteria on metal corrosion (Sheng et al., 2007; Moradi et al., 2011; Chen et al., 2014; Wang et al., 2014; Chen et al., 2015a; Lou et al., 2016), such as sulfate-reducing bacteria (SRB), ironoxidizing bacteria (FeOB), iron-reducing bacteria (FeRB) and acid-producing bacteria (APB). However, relatively few studies have focused on the involvement of fungi. In fact, a wide variety of fungi commonly existing in nature are capable of influencing metal corrosion (Salvarezza et al., 1983; Ayllon and Rosales, 1994; Hagenauer et al., 1994; Little et al., 1997; Videla et al., 1988; Galarde et al., 1999; Little and Ray, 2002; McNamara et al., 2005; Araya et al., 2007; Belov et al., 2008; Rosales and lannuzzi, 2008; Smirnov et al., 2008; Qu et al., 2015; Ching et al., 2016). For example, fungus Hormoconis (Cladosporium) resinae, a main microorganism found in the aviation fuel system, could affect the corrosion of aluminum fuel tanks with the corrosive acid metabolites or the corrosion inhibitor produced by the microorganism (Salvarezza et al., 1983; Videla et al., 1988; Ayllon and Rosales, 1994). Other fungal species, such as filamentous species Aspergillus niger and Penicillium frequentans, isolated from different corroded sites of aircraft, were reported to cause aggressive corrosions toward AA 7075 (Smirnov et al., 2008).

While accelerated corrosion due to fungi has been documented, several studies have reported that these fungal species could also act as corrosion inhibitors. For 
instance, $A$. niger and $P$. frequentans had been reported to protect pure aluminum from corrosion during two years of exposure, mainly by developing a passivating layer of aluminum oxides at localized corroded sites (Juzeliunas et al., 2005; Juzeliunas et al., 2007; Miecinskas et al., 2007). It seems fungal influenced corrosion depends on many factors including metal types, fungal species and exposure time (Juzeliunas et al., 2005; Araya et al., 2007; Juzeliunas et al., 2007; Miecinskas et al., 2007; Belov et al., 2008; Rosales and lannuzzi, 2008; Smirnov et al., 2008; Qu et al., 2015). Also, few studies have generated enough quantitative information on pitting morphology to permit detailed investigation on the corrosion mechanism of aluminum or its alloys by fungi.

In this study, we observed and characterized the corrosion of one aluminumcopper alloy, AA 2024-T3, corroded by a common fungal species A. niger in a humid and sterile atmospheric environment. We placed AA 2024-T3 coupons on potato dextrose agar (PDA) surfaces, and then dispersed an $A$. niger spore suspension onto the entire agar and coupon surfaces, and allowed the biofilm to develop and AA 2024-T3 to corrode. Parallel experiments with specimens exposed to $3.5 \mathrm{wt} \% \mathrm{NaCl}$ solution were conducted for comparison. The fungal biofilm examination, quantitative pit analysis, corrosion rate determination, and electrochemical measurement were carried out.

\section{Experimental Section}

\subsection{Materials and Methods}

Aluminum alloy 2024 (AA 2024-T3) sheet was purchased from McMaster-Carr. It contained Si 0.50 wt\%, Fe 0.50 wt\%, Cu $3.8 \sim 4.9$ wt\%, Mn $0.3 \sim 0.9$ wt\%, Mg $1.2 \sim 1.8$ wt $\%$, Cr $0.1 \mathrm{wt} \%$, Zn $0.25 \mathrm{wt} \%$, Ti $0.15 \mathrm{wt} \%$ and Al to $100 \mathrm{wt} \%$, as per ASTM standard B 209-96, (1996). The alloy had an ultimate tensile strength of 400-430 MPa, a yield strength of $270-280 \mathrm{MPa}$ or greater, and an elongation of $10-15 \%$. Potato dextrose broth, agar, acetone, ethanol, sodium chloride, and Tween-80 were from Sigma-Aldrich. Hexane (98.5 wt\%) and nitric acid were from Fisher Scientific. FilmTracer Live/Dead biofilm viability kit fluorescent staining solutions were purchased from Invitrogen. Deionized (DI) water with a conductivity of $1 \mu \mathrm{S} \mathrm{cm}^{-1}$ or less was prepared in-house.

\subsection{Preparation of AA 2024-T3 coupons}

Rectangular test specimens (i.e., coupons) of $20 \mathrm{~mm} \times 10 \mathrm{~mm} \times 0.4 \mathrm{~mm}$ were cut from an AA 2024-T3 sheet, which was pre-polished by the manufacturer. Coupons were sequentially cleaned in a sonicating bath with hexane, acetone, ethanol, and deionized water for 2 - 4 minutes each and then air dried. After weighing, coupons were soaked, in ambient condition, in a 75 vol\% ethanol solution for 24 hours for sterilization.

\subsection{Preparation of spore suspension}

The experimental procedure is illustrated in Fig. 1. The spore suspension of $A$. niger strain NRRL 13201 was prepared according to ASTM standard (ASTM G 21-90, 1990). Specifically, A. niger was cultured on potato dextrose agar (2.4 g potato dextrose, i.e., D-glucose, broth and $1.5 \mathrm{~g}$ agar per $100 \mathrm{ml} \mathrm{DI}$ water) at $23^{\circ} \mathrm{C}$ and more than $90 \%$ relative humidity for 1 - 3 weeks, and then the spores were collected and dispersed in a sterile Tween-80 solution $(0.5 \% \mathrm{v} / \mathrm{v})$ in a centrifuge tube. After the suspension was vigorously vortexed for breaking the spore clumps, a counting chamber (Bright-Line 
Hemacytometer, Hausser Scientific, PA, U.S.A.) was used for quantifying the spore concentration with the aid of a light microscope (Inverted microscope IX 70, Olympus American Inc., U.S.A.) coupled with a digital camera (MT 300, Amscope, CA, U.S.A.). The suspension was diluted with sterilized DI water to the standard concentration of $1 \times$ $10^{6}$ spore $\mathrm{ml}^{-1}$ for use in the corrosion studies.

\subsection{Corrosion studies}

Corrosion studies [see Fig. 1] were conducted in sterile six-well cell culture plates (CytoOne, USA Scientific Inc., USA) in a similar fashion for six systems marked as control, $\mathrm{NaCl}$, agar, $\mathrm{NaCl}+$ agar, $A$. niger, and $A$. niger + $\mathrm{NaCl}$ [Table 1]. PDA agars in the 6-well plates used were approximately $7 \mathrm{~mm}$ thick, corresponding to $\sim 6.3 \mathrm{ml}$ of agar gel that contained $96 \mathrm{wt}$ \% of water. Coupons taken from the ethanol solution were immediately rinsed with sterilized DI water to remove ethanol prior to being placed on the agar surfaces. For the cases with $\mathrm{NaCl}$, the ethanol sterilized AA2024-T3 coupons were dipped in a $3.5 \mathrm{wt} . \% \mathrm{NaCl}$ solution for $\sim 30 \mathrm{~s}$, and then removed and quickly placed either inside the well $(\mathrm{NaCl})$ or on top of the agar gel ( $\mathrm{NaCl}+$ agar). These coupons normally retained $\sim 0.1 \mathrm{ml}$ of residual $\mathrm{NaCl}$ solution on each of them. For the coupons to be exposed to A. niger, after placing the AA2024-T3 coupon on the agar, 1 $\mathrm{ml}$ aliquot of the prepared spore suspension was separately introduced into each well to provide a sufficient amount of $A$. niger spores in the system. For the coupon placed on the agar surface (four of the systems except control and $\mathrm{NaCl}$ ), the entire back surface was in intimate contact with the agar gel, and most of the liquid/solution on the front surface of the coupon drained into the agar gel.

Triplicates were used for each system. All six-well plates were covered by lids and kept in a glove box at $23{ }^{\circ} \mathrm{C}$ and more than $90 \%$ relative humidity for 21 days. To maintain this high humidity, $1 \mathrm{I}$ of sterile water was sprayed into the glove box every day. Corrosion studies were also repeated three times to ensure the reproducibility.

\subsection{Biofilm visualization and evaluation}

Biofilms were evaluated based on confocal laser scanning microscopy (CLSM) and scanning electron microscopy (SEM). CLSM scanning was used for visualizing the morphology of biofilm and the coupon surfaces. It was carried out using a confocal microscope (BX61W1 plus FV1000, Olympus) with its software FV10-ASW (Version 3.0, Olympus) after staining the biofilm with Live/Dead fluorescent stains (FilmTracer ${ }^{\mathrm{TM}}$ Live/Dead Biofilm Viability Kit, Cata\# L10316, Invitrogen) for 20 minutes. The green/red fluorescent light (for live/dead cells, respectively) was detected using excitation/emission wavelengths of $480 / 500 \mathrm{~nm}$ and $490 / 635 \mathrm{~nm}$, respectively. SEM characterization on a scanning electron microscope coupled with energy dispersive X-ray (SEM/EDX) (TM3000 Tabletop SEM, Hitachi High Technologies America, Dallas, TX) was carried out for assessing the morphology of biofilms on the front surface of each coupon after following fixation and dehydration procedures. Biofilms were fixed by immersion in a glutaraldehyde solution ( $2 \mathrm{wt} \%$ ) at $4{ }^{\circ} \mathrm{C}$ for 1 day, dehydrated in a series of ethanol solutions of increasing concentrations $(0,25,50,75$ and 100 vol\%) and then in a desiccator for 1 day at room temperature.

\subsection{Weight loss measurement}


141

142

143

144

145

146

147

148

149

150

151

152

153

154

155

156

157

158

159

160

161

162

163

164

165

166

167

168

169

170

171

172

173

174

175

176

177

178

179

180

181

182

183

184

185

186

187

Corrosion rates via weight loss were computed according to the equation in ASTM D 2688-05 (2005), after following the chemical cleaning procedures in the ASTM G1-03 standard (C.1.2 in Table A1.1) (2003). Coupons removed from the corrosion study systems were washed with a 75 vol\% solution of ethanol in water, and then brushed under flowing tap water to remove biofilms and corrosion products. Subsequently, dry coupons were immersed in a $69.2 \mathrm{wt} \%$ nitric acid solution for around 3 minutes to completely remove corrosion products, rinsed with DI water to remove the acid, and finally were dried under flowing air. The coupons before and after experiments were weighed using an analytical balance (E1RR80, Ohaus) with an accuracy of $0.1 \mathrm{mg}$. Then corrosion rates were calculated by using Equation 1 (ASTM D2688-05, 2005).

Corrosion rate $=W /(d$ a $t)$

Eq. 1

where $W$ is the weight loss; $d$ is the density of the metal (for aluminum, $d$ is $2.78 \mathrm{~g} \mathrm{~cm}^{-3}$ ), $t$ is the exposure time, and $a$ is the initial surface area of both sides (edge surfaces, accounting only $\sim 6 \%$ of the total surface area, were ignored). Results from all replicate experiments were averaged.

\subsection{Observations and analysis of pitting morphology}

The coupon surfaces and corrosion products were examined by SEM/EDX. A 3D optical microscope (infinite focus microscopy, IFM, Alicona Corporation, Austria) was used to obtain 3D images and surface roughness information. Roughness parameters were averaged or compared by scanning different locations (i.e. avoiding scratches and excluding edges) accounting for at least $50 \%$ of the entire surface. Areal surface roughness parameters were calculated according to EN ISO 4287 (1997), DIN 47761990 (1990), and the study by Stout et al. (2000). Parameters, such as $S_{k}$ (the height of core material or "kernel", representing the surface roughness), $S_{\mathrm{vk}}$ (the depth of valleys, i.e. pits), $V_{v v}$ (the volume of valley voids or pits), $S_{v}$ (the maximum valley depth of the selected area), and $S_{\mathrm{dr}}$ (the developed interfacial area ratio or $S_{\mathrm{dr}}=$ (actual surface area - projected surface area) / (projected surface area) $\times 100 \%$ ). Schematic diagrams for such parameters could be found in an earlier study (Chen and Ju, 2015b). The average pit depth could be estimated from the combination of $S_{k}+S_{v k}$. The maximum pit depth and pitted area percentage could be estimated based on the method proposed by Chen et. al. (2015b; 2016) as follows:
Pitted area percentage $=6.62 \times\left(S_{\mathrm{vk}} \times V_{\mathrm{vv}} / S_{\mathrm{dr}}\right)$
Eq. 2
Maximum pit depth $=0.96 \times\left(S_{\mathrm{v}}+S_{\mathrm{k}}\right)$
Eq. 3

The pitted area percentage could provide valuable information on both pit quantity and size, and would be useful for identifying coalesced pits.

\subsection{Metabolite analysis}

After the coupon was removed from each well, an agar disc was extracted by inserting a glass tube, and the exact mass was weighed. Three agar discs from three different wells were collected; each agar disc was placed in $2 \mathrm{ml}$ DI water inside a glass vial, and then vigorously vortexed. Each solution was filtered using a $0.32 \mu \mathrm{m}$ PVDF filter, and the solution was analyzed by a Shimadzu LC-10A high-performance liquid chromatography (HPLC) system (Shimadzu Corp., Columbia, MD) equipped with an Amninex HPX-87H column (Bio-Rad Laboratories Inc., USA), a UV-Vis detector (SPD$10 \mathrm{~A}$ ), and a refractive index detector. $\mathrm{A} 0.008 \mathrm{~N} \mathrm{H}_{2} \mathrm{SO} 4$ solution was used as the mobile phase at $0.6 \mathrm{ml} \mathrm{min}{ }^{-1}$ and the column temperature was set at $35^{\circ} \mathrm{C}$. Standard solutions 
188

189

190

191

192

193

194

195

196

197

198

199

200

201

202

203

204

205

206

207

208

209

210

211

212

213

214

215

216

217

218

219

220

221

222

223

224

225

226

227

228

229

230

231

232

of organic acid were used to generate calibrations for determining their presence and concentrations.

\section{Results and discussion}

\subsection{Biofilm morphology and development}

After 2 days, the agar and coupon surfaces turned slight yellowish and showed initial mycelial growth from the germinated spores [Fig. 2(A)]. After 21 days, a transparent and gel-like layer, which extended from the edges into the central region of the coupon (with a clear boundary), appeared on all inoculated coupons [Fig. 2(B)]. CLSM analysis revealed the presence of un-uniformly distributed biofilm with elongated and branched mycelial networks. The mycelial networks in the site (b), as shown in CLSM images, were much denser and thicker [with a thickness of $\sim 168 \mu \mathrm{m}$, Fig. 2(C)] than in site (a), which had a thickness of $\sim 54 \mu \mathrm{m}$ [Fig. 2(B)]. The SEM image on the central part [site (a)] of the coupon [Fig. 2(E)] showed, as indicated by arrows, several visible micro pits and trenching around white spots, most likely intermetallic particles in AA 2024-T3, formed under thinner hyphae layers. Along the edges of the coupon (site (b)), the mycelium networks were interconnected with some corrosion products [Fig. $2(\mathrm{~F})]$, more details of these corrosion products are described in section 3.4.

\subsection{Corrosion of AA 2024-T3 in the presence of $A$. niger}

Corrosion rates in the control and agar systems were relatively small and not statistically different $(p$-value $=0.78)$, with values of $2.5 \pm 1.1 \mu \mathrm{m} \mathrm{y}^{-1}$ and $2.7 \pm 1.7 \mu \mathrm{m} \mathrm{y}^{-1}$, respectively [Fig. 3]. The $\mathrm{NaCl}$ and $\mathrm{NaCl}+$ agar systems also had no statistically different corrosion rates ( $p$-value $=0.33$ ), but the values were higher, at $33.3 \pm 2.3 \mu \mathrm{m} \mathrm{y}^{-1}$ and $37.2 \pm 3.5 \mu \mathrm{m} \mathrm{y}^{-1}$, respectively, as compared to the control and agar systems. The results indicated that the presence of agar did not affect the corrosion rate of AA 2024-T3 under our experimental environment. Corrosion rates for coupons exposed to $A$. niger without and with $\mathrm{NaCl}$ were $127.3 \pm 9.3 \mu \mathrm{m} \mathrm{y}^{-1}$ and $149.0 \pm 7.8 \mu \mathrm{m} \mathrm{y}^{-1}$, respectively, while insignificantly different $(p$-value $=0.17)$ from each other, they were significantly greater $(\sim 4 \times)$ than the rates caused by $\mathrm{NaCl}$ alone. These results showed the presence of $A$. niger accelerated the corrosion process of AA 2024-T3.

The optical microscopy examination showed that coupons exposed to $A$. niger were severely corroded, forming many dark visible pits, had very corroded edges, and a layer of multi-colored corrosion products on the coupon (as shown in some of the images in the Supporting Information section). While the front surface, where A. niger biofilm was in direct contact with, had a few shallow and round micro-pits [Fig. 4(A)], the entire back surfaces were corroded with deep irregular pit clusters [Fig. 4(B)] and micro pits. It is worth noting that there was no fungal growth on the back surface. These results showed that, in the presence of $A$. niger, $A$. niger biofilm formed on the front surface of the coupon and produced metabolites, which likely distributed on the front surface and migrated into the agar gel, where the back surface of the coupon was in direct contact with, and caused the enhanced corrosion, including pitting corrosion, on both surfaces of the AA 2024-T3 coupon. 
Several studies reported the effect of $A$. niger on corrosion of aluminum and its alloys. Some demonstrated that this fungus caused corrosion damages (Hagenauer et al., 1994; Belov et al., 2008), while the others claimed that it protected pure aluminum from corrosion due to the formation of the passivating layer of aluminum oxides (Juzeliunas et al., 2005; Juzeliunas et al., 2007; Miecinskas et al., 2007). The acceleration or inhibition of aluminum alloy corrosion depends on factors such as culturing medium, metabolites produced by fungi, and alloy types (Juzeliunas et al., 2005; Juzeliunas et al., 2007; Miecinskas et al., 2007; Smirnov et al., 2008; Belov et al., 2008). In our short-term study, the results revealed that AA 2024-T3, an aluminumcopper alloy, was susceptible to pitting corrosion in the presence of $A$. niger.

A. niger is known for excreting many kinds of organic acids including citric acid, oxalic acid, succinic acid, malic acid, gluconic acid and fumaric acid (Sazanova et al., 2014). HPLC analysis of the aqueous solutions with samples taken from the agar gels after exposure to $A$. niger, showed that the dominant organic acid excreted by this $A$. niger strain was oxalic acid [Fig. 5], and its concentration increased with the exposure time to $A$. niger as the glucose was being consumed. It should be noted that HPLC analysis of the medium and the agar gel extracted at the beginning of the corrosion study (time 0 ) showed no obvious peaks for oxalic acid. We would also like to point out that oxalic acid is highly soluble in water (the solubility of oxalic acid in water is $143 \mathrm{~g} \mathrm{l}^{-1}$ at $25^{\circ} \mathrm{C}$ ), and due to the intimate contact of the coupon with the agar gel, the oxalic acid produced by $A$. niger dissolved in the thin liquid aqueous layer on the coupon, which drained into the agar gel and distributed throughout the gel. Since the gel contained $\sim 96$ wt.\% of water and had relative large pores ( $400 \mathrm{~nm}$ for a $2 \%$ agar gel) (Pernodet et al., 1997), the distribution of oxalic acid within the gel was expected to be relatively uniform. In fact, when samples were taken from different locations, such as near the top and the bottom of the gel, within the agar gel, the oxalic acid concentrations were found to be close to each other. The concentration of oxalic acid within the agar gel was found to be $\sim 0.068 \mathrm{M}$, and approximately accounted for $96 \%$ of the total organic acids detected after 21 days of exposure. The $\mathrm{pH}$ value in the gel, measured directly using a micro $\mathrm{pH}$ electrode, was 2.3, at day 21.

Oxalic acid excreting from $A$. niger was speculated to be the main cause of inducing severe corrosion of AA 2024-T3. Separate experiments were conducted by immersing AA 2024-T3 coupons in a $0.068 \mathrm{M}$ of the oxalic acid solution with a pH of 2.3 (i.e. $\mathrm{pH}$ was adjusted by $\mathrm{NaOH}$, since the $0.068 \mathrm{M}$ of oxalic acid solution had a $\mathrm{pH} \sim 1.5$ ) and utilizing electrochemical impendence spectroscopy (EIS) to monitor the corrosion. The corrosion rate calculated from the weight loss for 5 days exposure in the immersion experiment was $\sim 200 \mu \mathrm{m} \mathrm{y}^{-1}$, and the value calculated from EIS spectra was $\sim 180 \mu \mathrm{m}$ $\mathrm{y}^{-1}$ (more details on estimating the corrosion rate using EIS spectra can be found in the Supporting Information section). These values were in relatively good agreement with the corrosion rate of AA2024-T3 in the presence of $A$. niger for 21 days $\left(\sim 127 \mu \mathrm{m} \mathrm{y}^{-1}\right)$. It indicated that the main reason of corrosion in the fungal system was likely due to oxalic acid.

\subsection{Pit distribution and quantitation}

Various pits were formed on the AA2024-T3 coupon surfaces under different environments investigated in this study. The presence of corrosive species, i.e., $\mathrm{NaCl}$ 
and oxalic acid, was necessary for pitting, and pitting appeared to be associated with the high local concentration of these corrosive species. However, the severity of pitting was not necessarily well correlated with the weight loss values for AA2024-T3. For example, the corrosion rate based on weight loss was basically the same for the cases of $\mathrm{NaCl}$ and $\mathrm{NaCl}+$ agar, but the pit depths for the coupons associated with $\mathrm{NaCl}$ reached $\sim 10$ $\mu \mathrm{m}$ on the back surface [Fig. 4(D)] and $25 \mu \mathrm{m}$ on the front surface [Fig. S3(A)]. For the case of $\mathrm{NaCl}+$ agar, the pits were very heterogeneous. On the front surface of the coupon, pits as deep as $\sim 130 \mu \mathrm{m}$ in some locations (Fig. 4(E)) and $\sim 8 \mu \mathrm{m}$ in other locations [Fig. 4(F)] were observed, while on the rest of the coupon only shallow micro pits were noticed [Fig. S3(B)]. As a result, the average pit depth for this case was $\sim 22$ $\mu \mathrm{m}[(\mathrm{f})$ in Fig. 6(B)], and large standard deviations on the pitting parameters [case (f) in Fig. 6] were obtained. Pits were almost undetectable on the back surface of the coupons exposed to $\mathrm{NaCl}+$ agar [Fig. $\mathrm{S} 3(\mathrm{C})$ ].

For coupons exposed to $A$. niger, the central region of the front surface [site (a) in Fig. 2(B)] had a few shallow and round micro pits (a depth of $\sim 2 \mu \mathrm{m}$ ) [Fig. 4(A)], while at the edge [site (b) in Fig. 2(B)], many deeper pits and pit clusters (a depth of $15 \mu \mathrm{m}$ ) were observed [Fig. 4(B)]. As mentioned earlier, the biofilm located on site (a) was much thinner than that on site (b) [Fig. 2]. The coincidence suggests that the distribution of pits might have a spatial correlation with the biofilm thickness; in other words, more severe pitting occurred under a thicker biofilm [see the quantitative data, cases (b) and (c), in Fig. 6]. On the back surface, pits as deep as $\sim 110 \mu \mathrm{m}$ were observed, and the pit profile showed a "terraced" effect [Fig. 4(C)]. Therefore, the severe pitting in the presence of $A$. niger, due to the oxalic acid produced by this fungal strain, was comparable to that caused by $\mathrm{NaCl}$ for AA2024-T3 coupons.

In addition to IFM images presented in Fig. 4, SEM images were obtained to verify the presence of micro pits with wide bottoms (diameters of $\sim 10 \mu \mathrm{m}$ ) [Fig. 7(A)]. There were some corroded remnants inside the micro pits and slight trenching around isolated intermetallic particles (e.g., Cu-Al-Mg and Al-Cu-Fe-Mn, as the white spots indicated by arrows in Fig. 7(A)) in the central region of the front surface. Many severe irregular pit coalescences, clusters, cavities and even cracks were observed near and along the edge of the front surface [Fig. 7(B)] and on the back surface [Fig. 7(C)]. It is worth noting that many large pits were composed of a greater number of regular smaller pits [Fig. 7(D)]. In a separated experiment with AA 2024-T3 immersed in an oxalic acid solution for $96 \mathrm{~h}$, similar surface morphology with numerous micro-pits and pit clusters was observed [Fig. S5(A)].

Fig. 6 presents surface roughness parameters from the IFM scans (definitions of these parameters were provided in Section 2.7). The parameters used for pit quantification were: the average pit depth, the maximum pit depth and the pitted area percentage, which were estimated using Equations 2 and 3, and the pit volume ( $\left.V_{\mathrm{vv}}\right)$. The control sample [case (a) in Fig. 6] and the central region of the front surface of the coupon [case (b) in Fig. 6] in the presence of $A$. niger were almost non-pitted or micropitted [Figs. $4(A)$ and $7(A)$ ]. Their parameters did not differ significantly with the lowest values among all samples: the maximum pit depth of $\sim 10 \mu \mathrm{m}$, the average pit depth of $4 \mu \mathrm{m}$, the pitted area percentage of $\sim 0.8 \%$, and the pit volume of $\sim 0.1 \mathrm{ml} \mathrm{m}^{-2}$. The colonization of thin biofilm in the central region of the front surface initiated micro pitting, but these micro pits did not obviously alter the surface roughness significantly. However, 
all parameters for the coupon edge [case (c) in Fig. 6], where a much thicker biofilm was present, were statistically significantly different from those in the central region ( $p$-value $<0.05$ ), and a maximum depth of $\sim 47 \mu \mathrm{m}$ was observed. One thing worth noting is that, the most severely corroded regions of the edge, with metal mostly disintegrated, were not used in this pitting analysis. Only pits in the regions near the edge were quantified. The pit depth observed on the front surface was likely related to the biofilm thickness distribution. The back surface of coupons exposed to $A$. niger [case (d) in Fig. 6] displayed much more severe pitting corrosion with the maximum pit depth of $110 \mu \mathrm{m}$, the average pit depth of $\sim 12 \mu \mathrm{m}$, the pitted area percentage of $\sim 7.4 \%$, and the pit volume of $\sim 0.5 \mathrm{ml} \mathrm{m}^{-2}$. The pitting extent on the edge of the coupon exposed to $A$. niger and the back surface was comparable to that of coupons exposed to $\mathrm{NaCl}$ [back surface, case (e) in Fig. 6]. The coupon collected from the $\mathrm{NaCl}+$ agar system [case (f) in Fig. 6] also had high values of all these parameters, which could be the result of the local high $\mathrm{NaCl}$ concentration. The comparison of results [Figs. 3 and 6] among these systems showed that the weight loss values of AA 2024-T3 caused by $A$. niger was much higher than those of abotic systems and the pitting corrosion was comparable to the coupons exposed to $\mathrm{NaCl}$.

\subsection{Copper enrichment in the presence of $\boldsymbol{A}$. niger}

After removing the biofilm, it was noticed that a few shiny particles with size ranging from a few to tens of microns were randomly distributed on the coupon. The particles were also observed on the back surface [Fig. 8A] where the biofilm was not colonized. It seemed that most of these particles (tens of microns) were inside the pits. As shown in Fig. $8(\mathrm{C})$, the elemental percentage of $\mathrm{Al}$ decreased while the copper content increased for both site (a) (i.e. smooth site) and site (b) in Fig. 8(B) (i.e. copper enriched particles), as compared to the original AA 2024-T3. It should be noted that severe pitting corrosion was observed on the back surface without directly contacting $A$. niger. The copper enrichment and severe pitting were probably induced by the metabolite, oxalic acid, which could accumulate underneath the coupon and diffuse through the agar. AA 2024-T3 contains 4\% Cu and $~ 1.5 \% \mathrm{Mg}$, and is susceptible to localized corrosion due to the presence of intermetallic particles. Copper enrichment could be attributed to the de-alloying of intermetallic particles of $\mathrm{Al}_{2} \mathrm{CuMg}$ or dealumination of $\mathrm{Al}_{2} \mathrm{Cu}$ (Chen et al., 1996; Buchheit et al., 1997). Similar results were observed when the AA 2024-T3 coupons were immersed in a $0.068 \mathrm{M}$ oxalic acid solution for $96 \mathrm{~h}$ [Fig. 9]. These observations indicated that the corrosion of AA 2024-T3 due to oxalic acid produced by $A$. niger also exhibited the phenomenon of copper enrichment that generally occurred with corrosion of AA2024-T3.

\section{Conclusion}

The presence of $A$. niger enhanced the corrosion rate based on the weight loss to a value more than 4 times of those of $\mathrm{NaCl}$ or control systems. Results of pit morphology and quantitative pit parameters (e.g. maximum and average pit depths) showed that severe pitting corrosion was observed when AA 2024-T3 coupons were exposed to $A$. niger. The pitting was comparable to those AA 2024-T3 coupons exposed to $\mathrm{NaCl}$. The colonization of biofilm on the front coupon surface induced micro-pitting at the center and severe pitting along the edge, which was roughly correlated to the spatial biofilm 
371 distribution. The presence of $A$. niger caused depletion of aluminum and copper 372 enrichment. The cause of corrosion was found to be related to the dominant acid 373 metabolite, oxalic acid, produced by $A$. niger under our experimental conditions.

\section{Acknowledgements}

We greatly appreciate Dr. Brenda J. Little for her valuable comments and suggestions on our manuscript and Dr. Jason S. Lee for his insights of studying AA 2024 corrosion in the presence of $A$. niger under a humid environment on potato dextrose agar. The authors also would like to acknowledge the help of Dr. Lingyan Li, Ms. Krutika Invally and Ms. Yajie Chen for IFM and CLSM characterizations, and Mr. Zhipeng Zeng for EIS measurements. This work is associated with the Corrosion and Reliability Engineering program at The University of Akron and in participation with the DoD Technical Corrosion Collaboration supported by the U.S. Department of Defense Office of Corrosion Policy and Oversight. The research is administered by the US Air Force Academy under agreement number FA7000-10-2-0013 (Projects FY11-TCC8 and FY12TCC2 to The University of Akron). 


\section{References:}

389

390

391

392

393

394

395

396

397

398

399

400

401

402

403

404

405

406

407

408

409

410

411

412

413

414

415

416

417

418

419

420

421

422

423

424

425

426

427

428

429

430

431

432

AlAbbas, F.M., Williamson, C., Bhola, S.M., Spear, J.R., Olson, D.L., Mishra, B., Kakpovbia, A.E., 2013. Influence of sulfate reducing bacterial biofilm on corrosion behavior of low-alloy, high-strength steel (API-5L X80). International Biodeterioration \& Biodegradation 78, 34-42, DOI: 10.1016/j.ibiod.2012.10.014.

Araya, R., Bobadilla, C., Vera, R., Rosales, M., 2007. Biochemical analysis of the Hormoconis resinae fungal mycelium in the corrosion of aeronautical aluminium alloys. Revista de Metalurgia , 228-236, DOI: 10.3989/revmetalm.2007.v43.i3.68.

ASTM G 21-90, 1990. Determining resistance of synthetic polymeric materials to fungi. ASTM International, West Conshohocken, Philadelphia,

ASTM B 209-96, 1996. Aluminum and aluminum-alloy sheet and plate. ASTM International, West Conshohocken, Philadelphia,

ASTM G1-03, 2003. Standard practice for preparing, cleaning, and evaluating corrosion test specimens. ASTM International, West Conshohocken, Philadelphia.

ASTM D 2688-05, 2005. Standard test method for corrosivity of water in the absence of heat transfer (weight loss method). ASTM International, West Conshohocken, Philadelphia,

Ayllon, E.S., Rosales, B.M., 1994. Electrochemical test for predicting microbiologically influenced corrosion of aluminum and AA 7005 alloy. Corrosion 50, 571-575, DOI: 10.5006/1.3293527.

Belov, D.V., Sokolova, T.N., Smirnov, V.F., Kuzina, O.V., Kostyukova, L.V., Kartashov, V.R., 2008. Corrosion of aluminum and its alloys under the effect of microscopic fungi. Protection of Metals 22, 737-742, DOI: 10.1134/S0033173208070151.

Buchheit, R.G., Grant, R.P., Hlava, P.F., McKenzie, B., Zender, G.L., 1997. Local dissolution phenomena associated with $\mathrm{S}$ phase $\left(\mathrm{Al}_{2} \mathrm{CuMg}\right)$ particles in aluminum alloy 2024-T3. Journal of the Electrochemical Society 144, 2621-2628, DOI: 10.1149/1.1837874.

Chen, G.S., Gao, M., Wei, R.P., 1996. Microconstituent-induced pitting corrosion in aluminum alloy 2024-T3. Corrosion 52, 8-15, DOI: 10.5006/1.3292099.

Chen, Y., Howdyshell, R., Howdyshell, S., Ju., L.-K., 2014. Characterizing pitting corrosion caused by a long-term starving sulfate-reducing bacterium surviving on carbon steel and effects of surface roughness. Corrosion 70, 767-780.

Chen, Y., Tang, Q., Senko, J.M., Cheng, G., Zhang Newby, B.-m., Castaneda, H., Ju, L.-K., 2015a. Long-term survival of Desulfovibrio vulgaris on carbon steel and associated pitting corrosion. Corrosion Science 90, 89-100, DOI: 10.1016/j.corsci.2014.09.016.

Chen, Y., Ju, L.K., 2015b. Method for fast quantification of pitting using 3D surface parameters generated with infinite focus microscope. Corrosion 71, 1184-1196, DOI: 10.5006/1556.

Chen, Y., Torres, J., Castaneda, H., Ju, L.-K., 2016. Quantitative comparison of anaerobic pitting patterns and damage risks by chloride versus Desulfovibrio vulgaris using a fast pitting-characterization method. International Biodeterioration \& Biodegradation 109, 119-131, DOI:10.1016/j.ibiod.2016.01.012.

Ching, T.H., Yoza, B.A., Wang, R., Masutani, S., Donachie, S., Hihara, L., Li, Q.X., 2016. Biodegradation of biodiesel and microbiologically induced corrosion of 1018 steel by 
Moniliella wahieum Y12. International Biodeterioration \& Biodegradation 108, $122-$ 126, DOI:10.1016/j.ibiod.2015.11.027.

DIN 4776:1990, 1990. Determination of surface roughness parameters $R_{k}, R_{p k}, R_{v k}, M_{r 1}$, $\mathrm{M}_{\mathrm{r} 2}$ serving to describe the material component of roughness profile. Berlin, Germany.

Galarde, C.C., Bento, F.M., Kelley, J., 1999. Microbial contamination of stored hydrocarbon fuels and its control. Revista de Microbiologia 30, 01-10, DOI: 10.1590/S0001-37141999000100001.

Giacobone, A.F.F., Rodriguez, S.A., Burkart, A.L., Pizarro, R.A., 2011. Microbiological induced corrosion of AA 6061 nuclear alloy in highly diluted media by Bacillus cereus RE 10. International Biodeterioration \& Biodegradation 65, 1161-1168, DOI:10.1016/j.ibiod.2011.08.012.

Hagenauer, A., Hilpert, R., Hack, T., 1994. Microbiological investigations of corrosion damages in aircraft. Werkstoffe Und Korrosion-Materials and Corrosion 45, 355360, DOI: 10.1002/maco.19940450606.

ISO 4287:1997, 1997. Geometrical product specifications (GPS) -surface texture: profile method - terms, definitions and surface texture parameters. ISO, Geneva, Switzerland.

Jackson, 2013. The cost of corrosion exceeded \$1 trillion in United States in 2013. G2MT Laboratories, online at http://www.g2mtlabs.com/2011/06/nace-cost-ofcorrosion-study-update, access 2015.

Juzeliunas, E., Ramanauskas, R., Lugauskas, A., Samulevičienè, M.,, Leinartas, K., 2005. Microbially influenced corrosion acceleration and inhibition. EIS study of $\mathrm{Zn}$ and Al subjected for two years to influence of Penicillium frequentans, Aspergillus niger and Bacillus mycoides. Electrochemistry Communications 7, 305-31, DOI: 10.1016/j.elecom.2005.01.012 .

Juzeliunas, E., Ramanauskas, R., Lugauskas, A., Leinartas, K., Samuleviciene, M., Sudavicius, A., Juskenas, R., 2007. Microbially influenced corrosion of zinc and aluminium - two-year subjection to influence of Aspergillus niger. Corrosion Science 49, 4098-4112, DOI:10.1016/j.corsci.2007.05.004.

Little, B.J., Ray, R.I., Lee, J.S., 1997. An overview of microbiologically influenced corrosion in aircraft. DTIC Document (no. NRL/PP/7303/02/0008) http://oai.dtic.mil/oai/oai?verb=getRecord\&metadataPrefix=html\&identifier=ADA413 $\underline{907}$

Little, B.J., Ray, R.I., 2002. The role of fungi in microbiologically influenced corrosion. DTIC Document (no. NRL/PP/7302-02-0006) http://oai.dtic.mil/oai/oai?verb=getRecord\&metadataPrefix=html\&identifier=ADA414 034

Little, B.J., Mansfeld, F.B., Arps, P.J.,Earthman, J.C., 2007. Microbiologically influenced corrosion, in: Revie, R.W.,(Ed), Encyclopedia of Electrochemistry, Wiley-VCH Verlag GmbH \& Co. KGaA, US, pp. 1-2 .

Lou, Y., Lin, L., Xu, D., Zhao, S., Yang, C., Liu, J., Zhao, Y., Gu, T., Yang, K., 2016. Antibacterial ability of a novel Cu-bearing 2205 duplex stainless steel against Pseudomonas aeruginosa biofilm in artificial seawater. International Biodeterioration \& Biodegradation 110, 199-205, DOI: 10.1016/j.ibiod.2016.03.026. 
McNamara, C.J., Perry, T.D., Leard, R., Bearce, K., Dante, J., Mitchell, R., 2005. Corrosion of aluminum alloy 2024 by microorganisms isolated from aircraft fuel tanks. Biofouling 21, 257-265, DOI:10.1080/08927010500389921.

Miecinskas, P., Leinartas, K., Uksiene, V., Juzeliunas, E., 2007. QCM study of microbiological activity during long-term exposure to atmosphere - aluminium colonisation by Aspergillus niger. Journal of Solid State Electrochemistry 11, 909913, DOI: 10.1007/s10008-007-0286-4.

Moradi, M., Duan J., Ashassi-Sorkhabi, H., Luan, X., 2011. De-alloying of 316 stainless steel in the presence of a mixture of metal-oxidizing bacteria. Corrosion Science 53, 4282-4290, DOI:10.1016/j.corsci.2011.08.043.

Pernodet, N., Maaloum, M. and Tinland, B, 1997. Pore size of agarose gels by atomic force microscopy. Electrophoresis, 18, 55-58, DOI: 10.1002/elps.1150180111.

Qu, Q., Wang, L., Li, L., He, Y., Yang, M., Ding, Z., 2015. Effect of the fungus, Aspergillus niger, on the corrosion behaviour of AZ31B magnesium alloy in artificial seawater. Corrosion Science 98, 249-259, DOI:10.1016/j.corsci.2015.05.038.

Rajasekar, A., Ting, Y.P., 2010. Microbial corrosion of aluminum 2024 aeronautical alloy by hydrocarbon degrading bacteria Bacillus cereus ACE4 and Serratia marcescens ACE2. Industrial \& Engineering Chemistry Research 49, 6054-6061, DOI: 10.1021/ie100078u.

Rosales, B.M., lannuzzi, M., 2008. Aluminium AA2024 T351 aeronautical alloy - Part 1. Microbial influenced corrosion analysis. Materials Science and Engineering A 472, 15-25, DOI:10.1016/j.msea.2007.06.079.

Salvarezza, R.C., Demele, M.F.L., Videla, H.A., 1983. Mechanisms of the microbial corrosion of aluminum alloys. Corrosion 39, 26-32, DOI: 10.5006/1.3580810.

Sazanova, K.V., Shchiparev, S.M., Vlasov, D.Y., 2014. Formation of organic acids by fungi isolated from the surface of stone monuments. Microbiology 83, 516-522, DOI:10.1134/S002626171405021X.

Sheng, X.X., Ting, Y.P., Pehkonen, S.A., 2007. The influence of sulphate-reducing bacteria biofilm on the corrosion of stainless steel AISI 316. Corrosion Science 49, 2159-2176, DOI:10.1016/j.corsci.2006.10.040.

Smirnov, V.F., Belov, D.V., Sokolova, T.N., Kuzina, O.V., Kartashov, V.R., 2008. Microbiological corrosion of aluminum alloys. Applied Biochemistry and Microbiology 44, 192-196, DOI:10.1134/S0003683808020117.

Sowards, J.W., Mansfield, E., 2014a. Corrosion of copper and steel alloys in a simulated underground storage-tank sump environment containing acid-producing bacteria. Corrosion Science 87, 460-471, DOI:10.1016/j.corsci.2014.07.009.

Sowards, J.W., Williamson, C.H.D., Weeks, T.S., McColskey, J.D., Spear, J.R., 2014b. The effect of Acetobacter sp. and a sulfate-reducing bacterial consortium from ethanol fuel environments on fatigue crack propagation in pipeline and storage tank steels. Corrosion Science 79, 128-138, DOI:10.1016/j.corsci.2013.10.036.

Stout, K.J., Sullivan, P.J., Dong, W., Mainsah, E., Luo, N., Mathia, T., Zahouani, H., Stout, K., 2000. Development of methods for the characterisation of roughness in three dimensions, in: K.J. Stout (Ed), Elsevier, Oxford, UK.

Teng, F., Guan, Y.T., Zhu, W.P., 2008. Effect of biofilm on cast iron pipe corrosion in drinking water distribution system: corrosion scales characterization and microbial community structure investigation. Corrosion Science 50, 2816-2823, DOI:10.1016/j.corsci.2008.07.008. 
525 Videla, H. A., Guiamet, P.S., Do Vale., S.M., Reinoso, E.H., 1988. Effects of fungal and 526 bacterial contaminants of kerosene fuels on the corrosion of storage and distribution 527 systems. Corrosion/1988 paper no.91, NACE International, Houston, TX.

528 Wang, H., Ju, L.-K., Castaneda, H., Cheng, G., Zhang Newby, B.-m., 2014. Corrosion of 529 carbon steel $\mathrm{C} 1010$ in the presence of iron oxidizing bacteria Acidithiobacillus 530 ferrooxidans. Corrosion Science 89, 250-257, DOI:10.1016/j.corsci.2014.09.005. 


\section{Captions}

532 Fig. 1. Schematic representation of the experimental procedure utilized to follow AA

Fig. 2. Representative images of the evolution of AA 2024 coupons on agar dispersed with $A$. niger spores after 2 days $(A)$ and 21 days (B). A biofilm with a thinner (a) and a thicker (b) region was observed. Their corresponding CLSM top view images (C and D) are also shown, with the thicker and thinner regions having a thickness of $\sim 168 \mu \mathrm{m}$ and $\sim 54 \mu \mathrm{m}$, respectively. The SEM images of biofilm and corrosion products on the center region (site a) and the edge (site b) in (B) are shown in (E) and (F), respectively. (E) shows micro pits and trenching around intermetallic particles (indicated by arrows) under the thinner biofilm. Image (F) shows corrosion products of aluminum oxides and copper particles (as shown by arrows) under the thicker biofilm. The scale bars in (E) and (F) are $100 \mu \mathrm{m}$ and $500 \mu \mathrm{m}$, respectively.

Fig. 3. Corrosion rates calculated from weight loss of the coupons after 21 days exposure to $A$. niger are presented. The same letters on the corrosion rate bars indicate no significant statistical difference amongst coupons subjected to those conditions. The average and error bar for each data point presented were from the measurement of at least six samples.

Fig. 4. IFM images of the entire coupon surface $(10 \mathrm{~mm} \times 20 \mathrm{~mm})$, 3D view $(286 \mu \mathrm{m} \times$ $217 \mu \mathrm{m})$ and cross-sectional depth profiles of the center region $(A)$ and the edge of the front $(B)$ and the back $(C)$ surface of coupons associated with $A$. niger, the back surface of coupons associated with $\mathrm{NaCl}(\mathrm{D})$ and the front surface associated with the most severely pitted area $(E)$ and less severely pitted area $(F)$ of $\mathrm{NaCl}+$ agar, respectively. The 3D view for each case is indicated by the red squares. White lines on 3D views show the cross sections selected for the profiles. The red boxes are used to indicate the location of the 3D view scans, and they are not drawn to scale.

Fig. 5. (A) HPLC spectra of the oxalic acid standard and the substances in the agar gel after 0,3 and 21 days exposure to $A$. niger, and (B) the concentrations of oxalic acid and $\mathrm{D}$-glucose in the agar gel as function of exposure time to $A$. niger.

Fig. 5. The maximum pit depth $(A)$, average pit depth $(B)$, pitted area percentage $(C)$, and pit volume (D) obtained from IFM scans. The samples include control sample (a), the central region (b) and the edge of front surface exposed to A. niger (c), the back surface of coupons exposed to $A$. niger (d), the back surface of coupon exposed to $\mathrm{NaCl}$ (e), and the front surface of coupon exposed to $\mathrm{NaCl}+$ agar (f).

Fig. 7. SEM images of a coupon exposed to $A$. niger for 21 days: the center region (A) and edge (B) of the front surface, and the back surface (B and $C)$. Trenching around intermetallic particles and micro-pitting are shown by arrows in image (A). Images $C$ and $D$ show cracks and pit clusters. The scale bars in (A-C) and (D) are $100 \mu \mathrm{m}$ and $30 \mu \mathrm{m}$, respectively.

Fig. 8. The representing SEM images ( $A$ and $B$ ) of the back surface of a coupon exposed to $A$. niger are presented. The element mapping of $\mathrm{Al}, \mathrm{Cu}, \mathrm{O}$ and $\mathrm{C}$ from EDX analysis for image (B) is shown beneath the images, the element percentages for selective sites $(a$ and $b)$ in $(B)$ are summarized in $(C)$ along with those of the original coupon from the EDX analysis. Copper enriched particles were observed on the back surfaces. The scale bars in (A) and (B) are $100 \mu \mathrm{m}$ and $20 \mu \mathrm{m}$, respectively. 
576 Fig.9. A SEM image and the corresponding EDX element mapping for coupons exposed 577 to the oxalic acid solution $(0.068 \mathrm{M}$ and $\mathrm{pH} 2.3)$ for 96 hours. Corrosion products of 578 copper-enriched particles and aluminum oxides/oxalates are verified. The scale bar of 579 the SEM image is $20 \mu \mathrm{m}$.

580 Table 1. The corrosion study details for control and biotic samples 


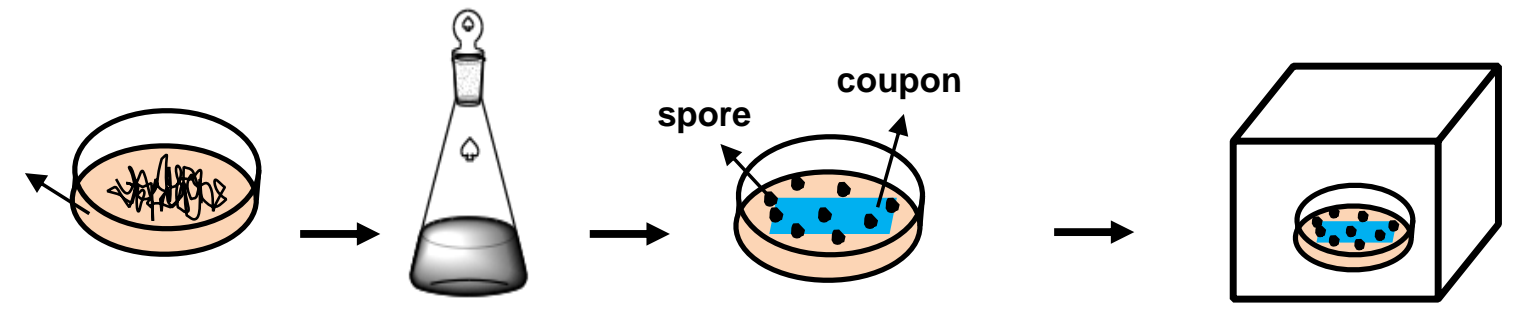

Culture fungus on Prepare spore potato dextrose agar suspension in (PDA)
Place a coupon on the PDA and disperse the spore suspension
Cover it and keep it at the constant temperature and high relative humidity $(\mathrm{RH}>90 \%)$ 

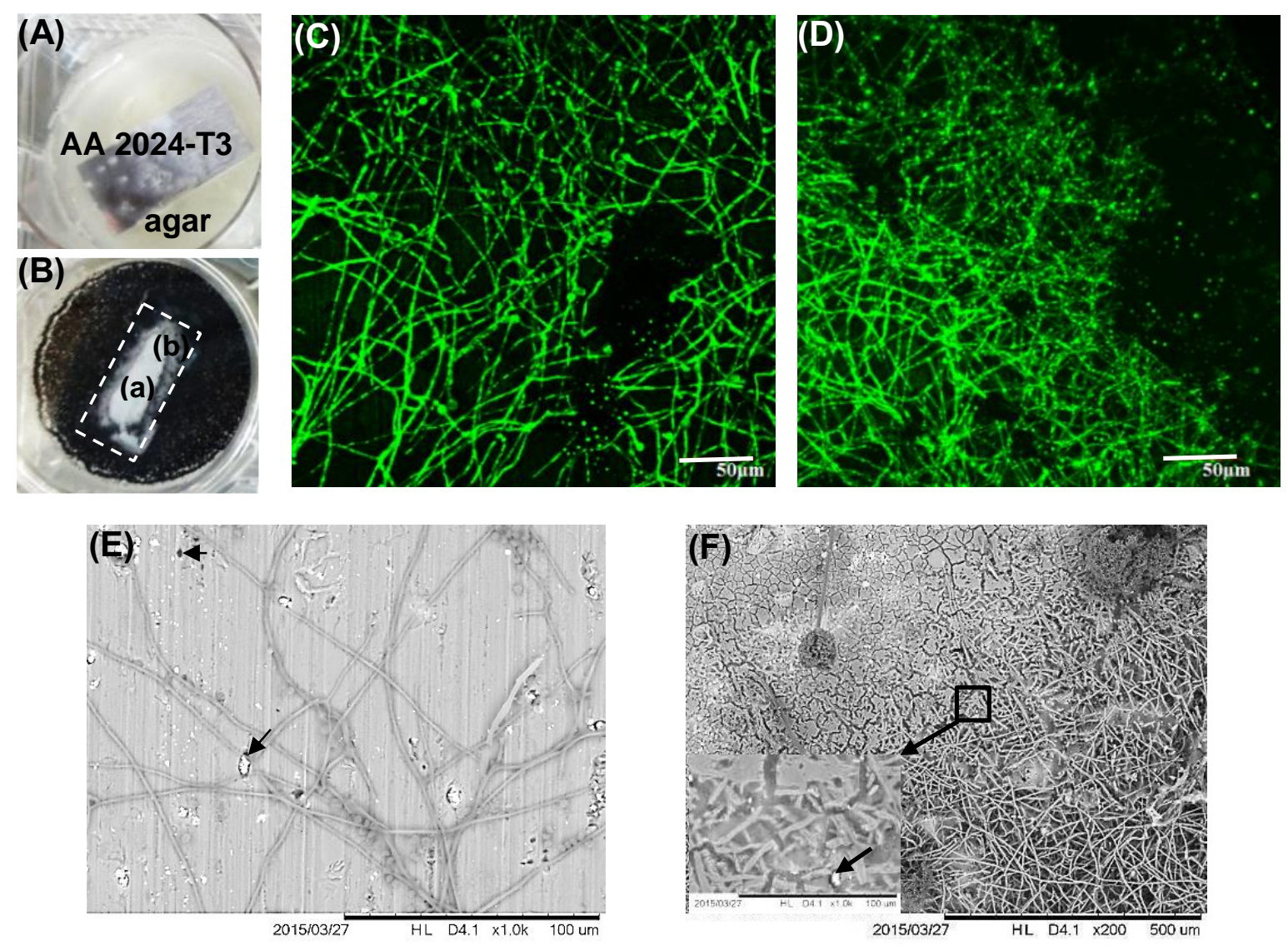

Fig. 2 


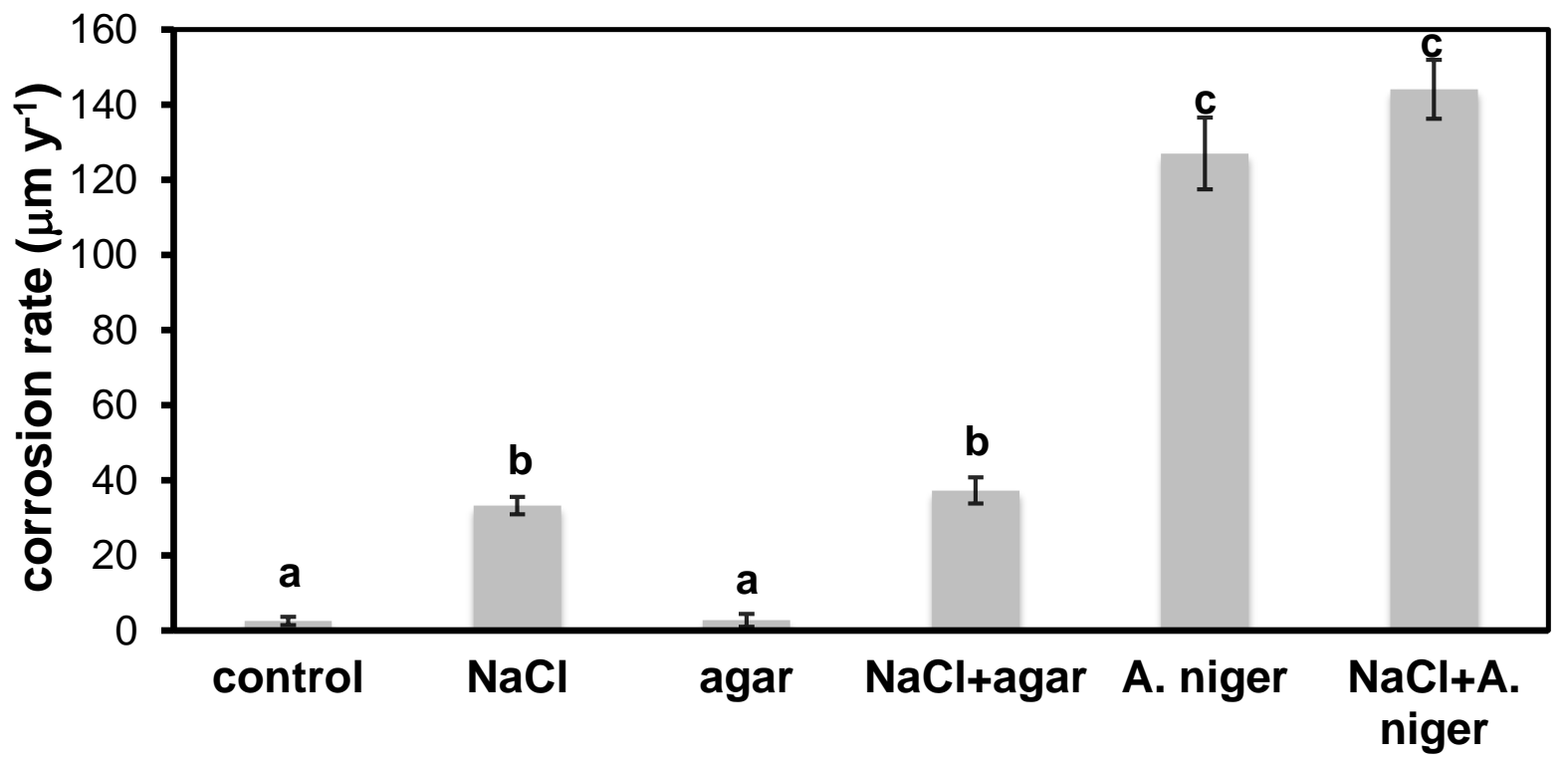

Fig. 3 
(A)
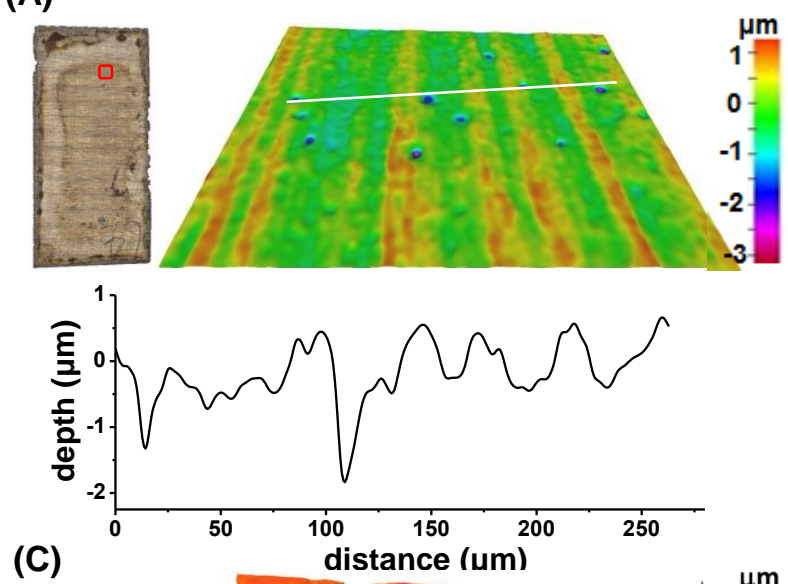

(C)

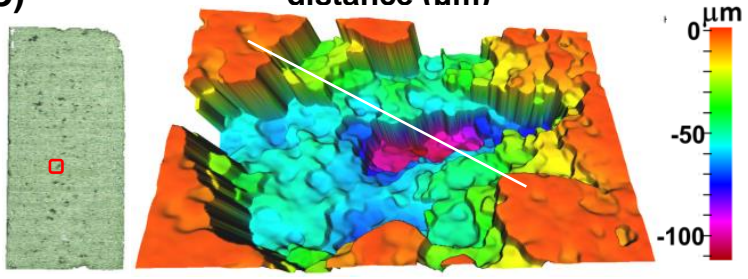

(E)
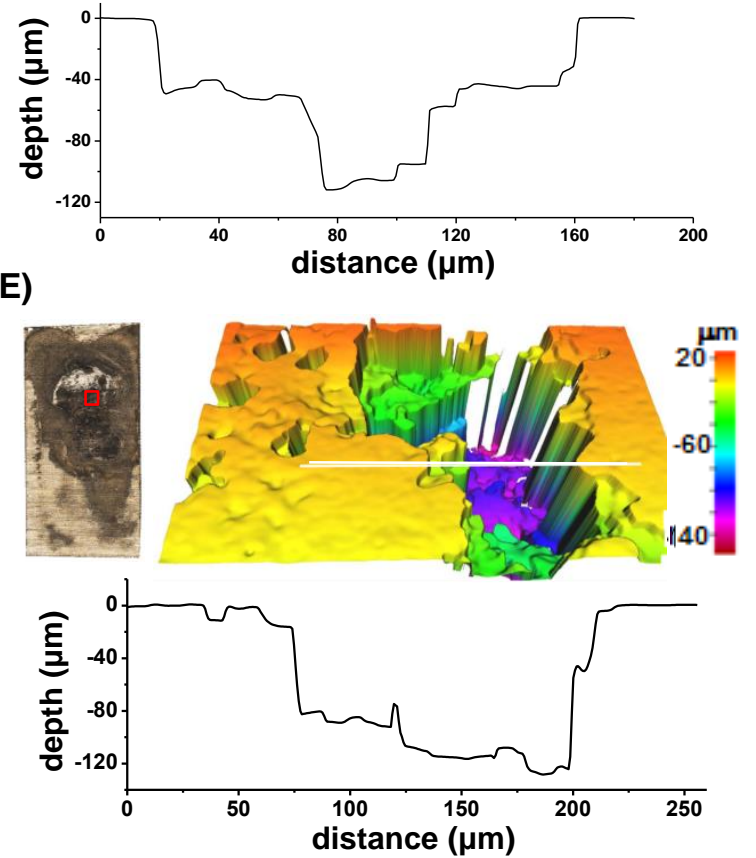

(B)
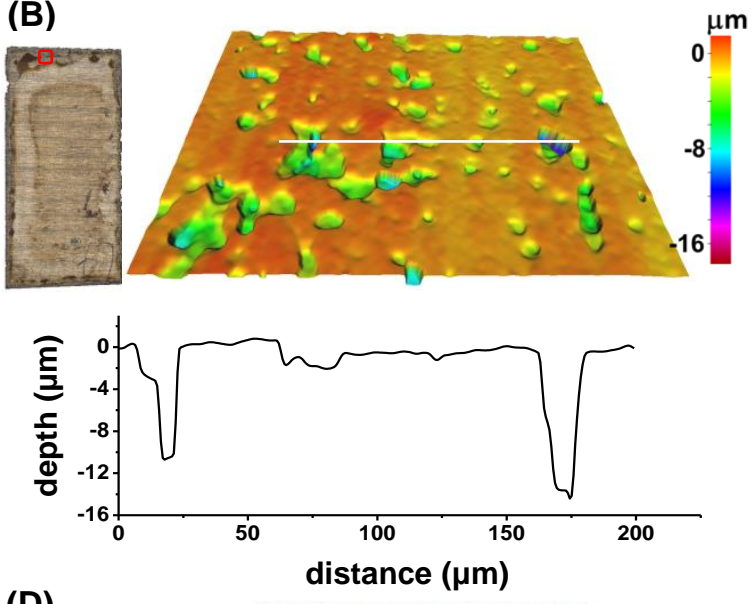

(D)
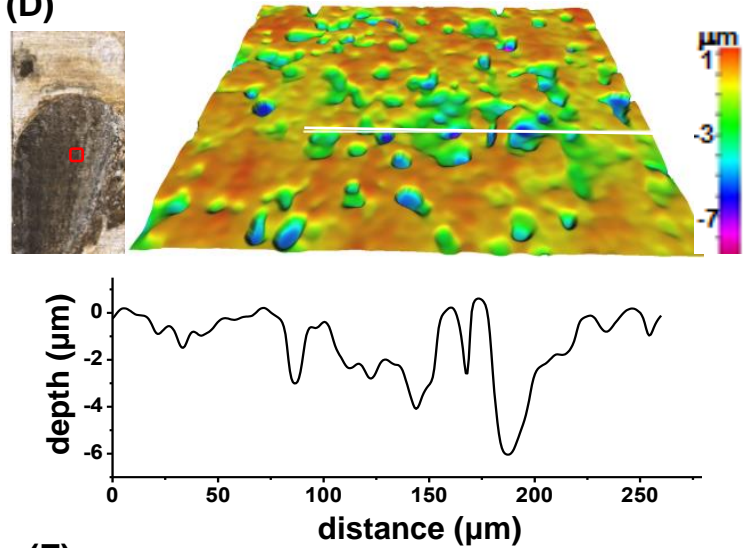

(F)

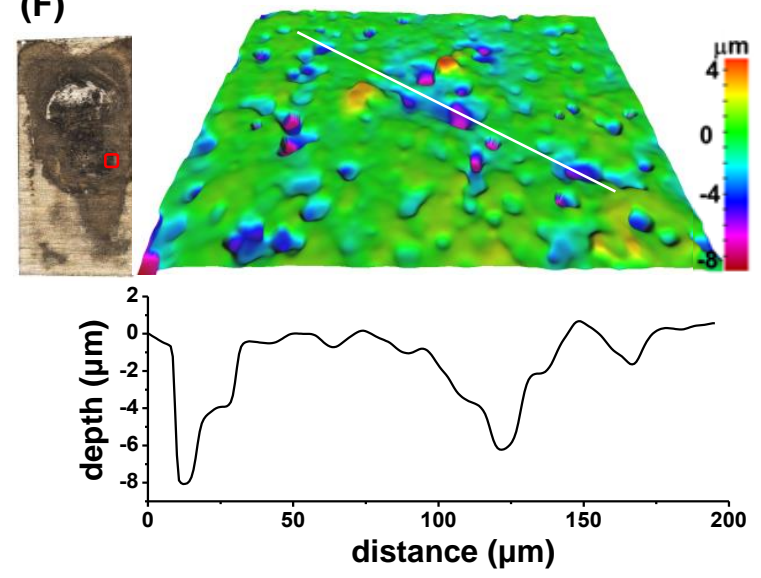


(A)

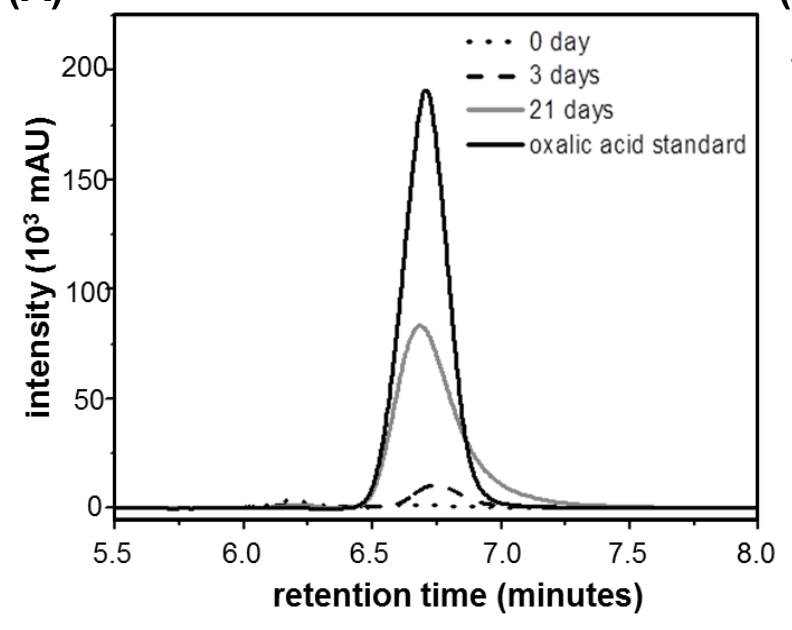

(B)

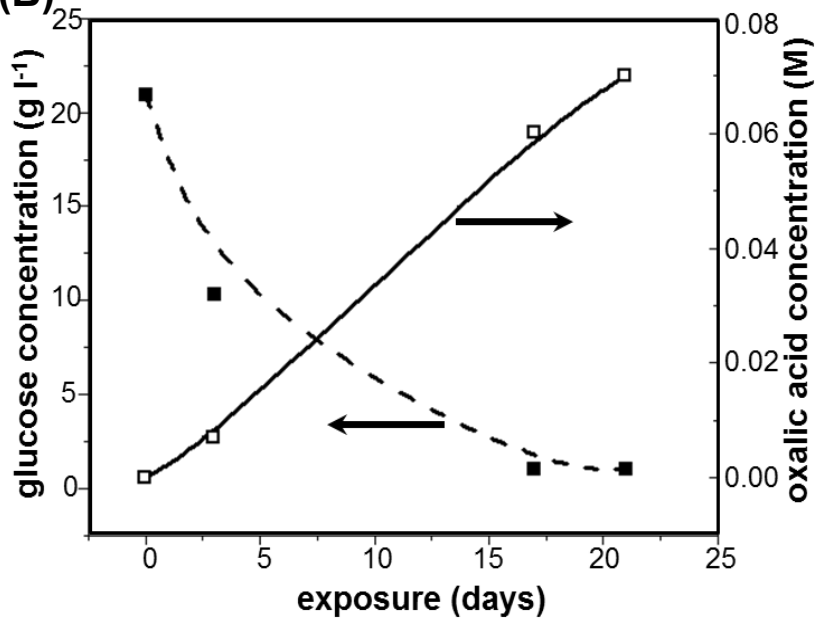

Fig. 5 

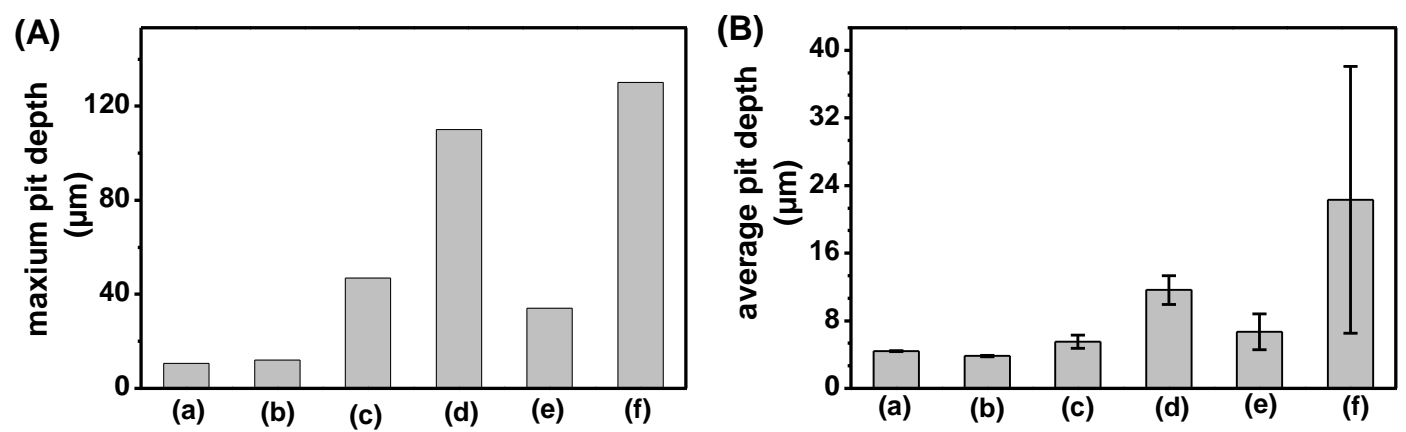

(C)
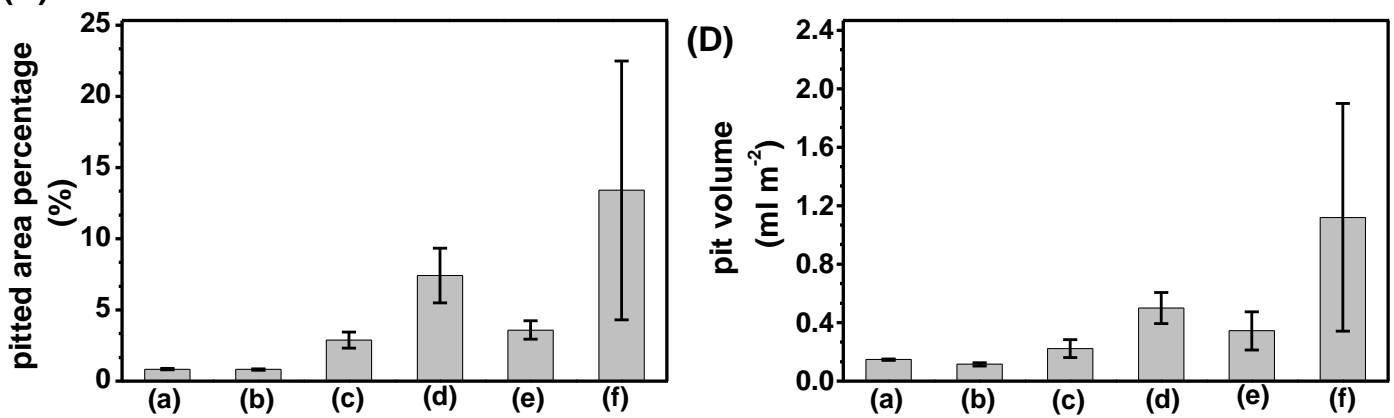

Fig. 6 

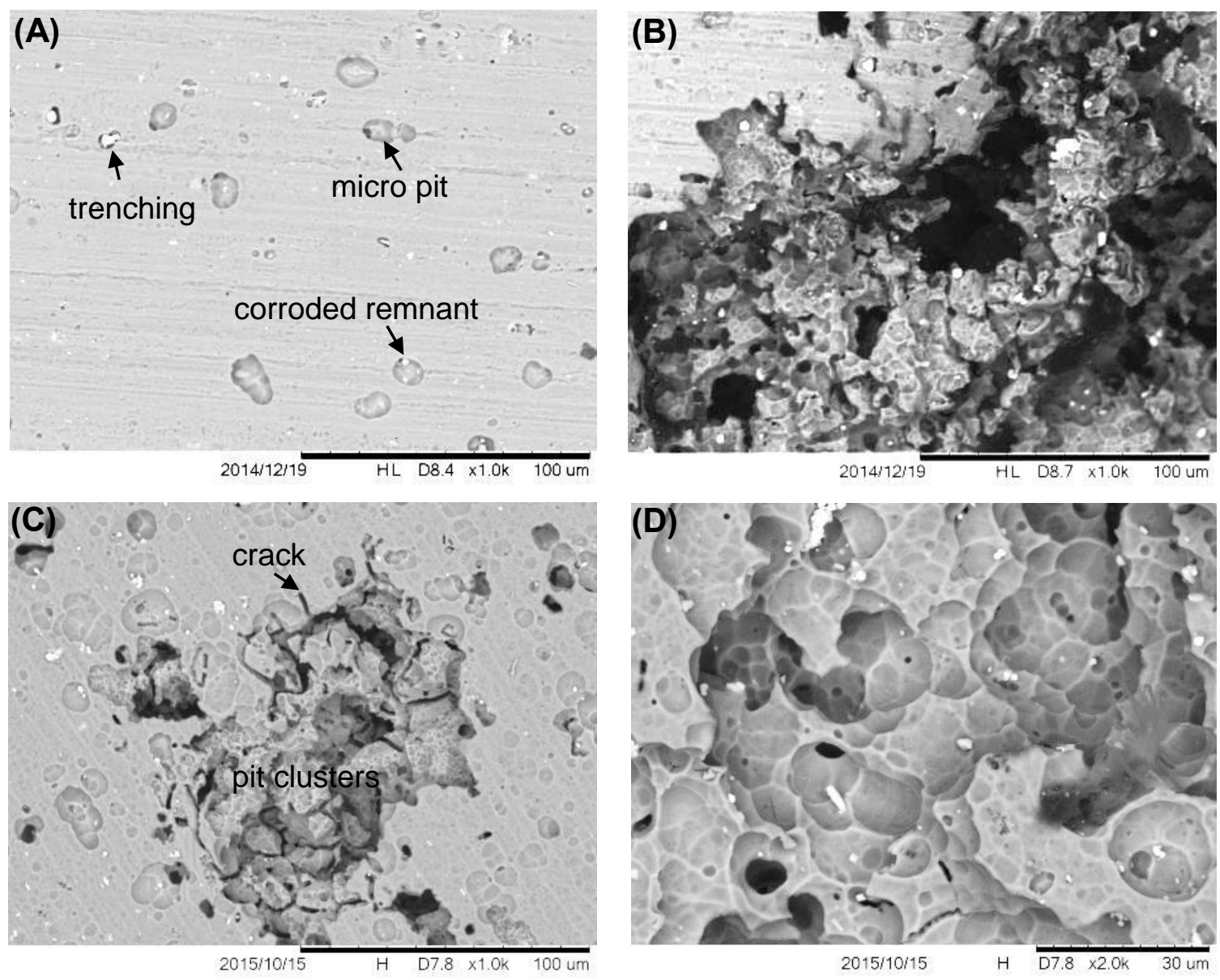

Fig. 7 


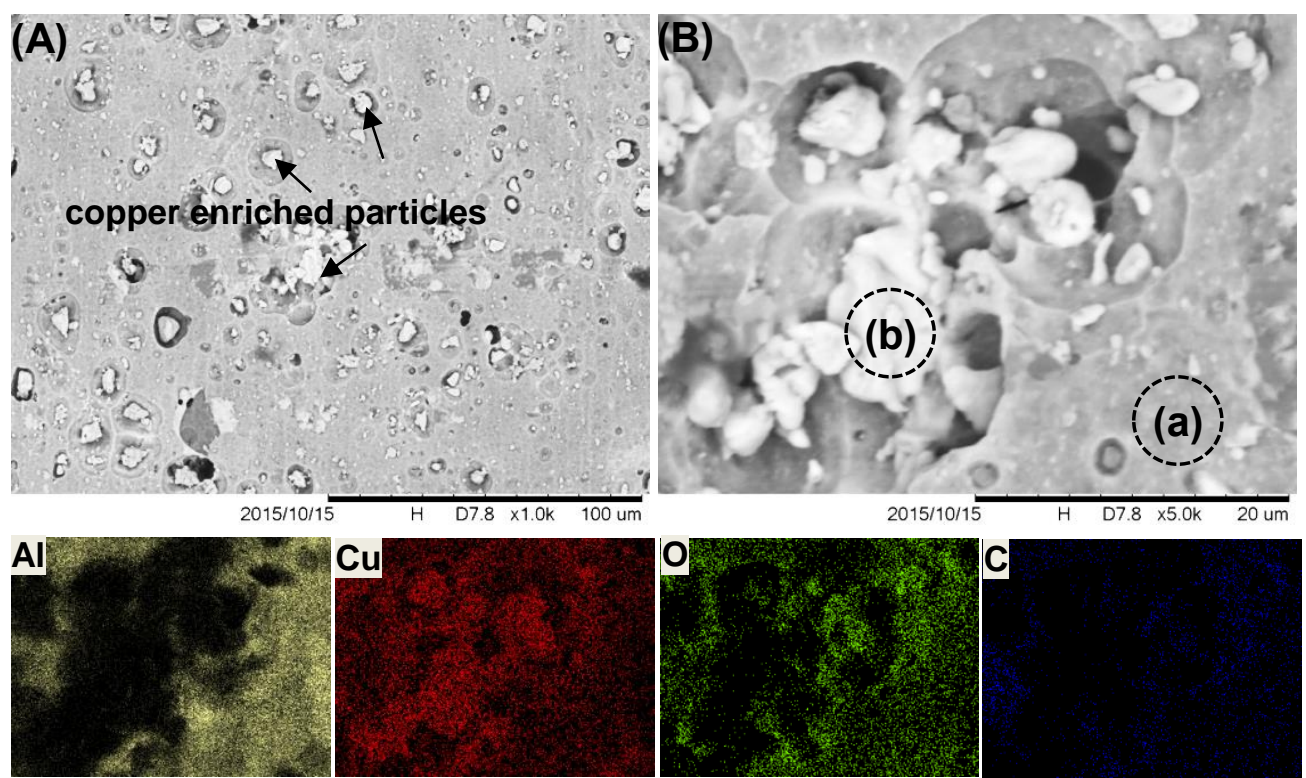

(C)

\begin{tabular}{ccccc}
\hline & \multicolumn{4}{c}{ Mass percentage (\%) } \\
\cline { 2 - 5 } site (a) in (B) & $\mathrm{Al}$ & $\mathrm{Cu}$ & $\mathrm{C}$ & $\mathrm{O}$ \\
\cline { 2 - 5 } site (b) in (B) & 48.9 & 7.1 & 29.7 & 13.3 \\
original AA 2024 & 8.7 & 84.2 & 3.5 & 3.6 \\
\hline
\end{tabular}

Fig. 8 

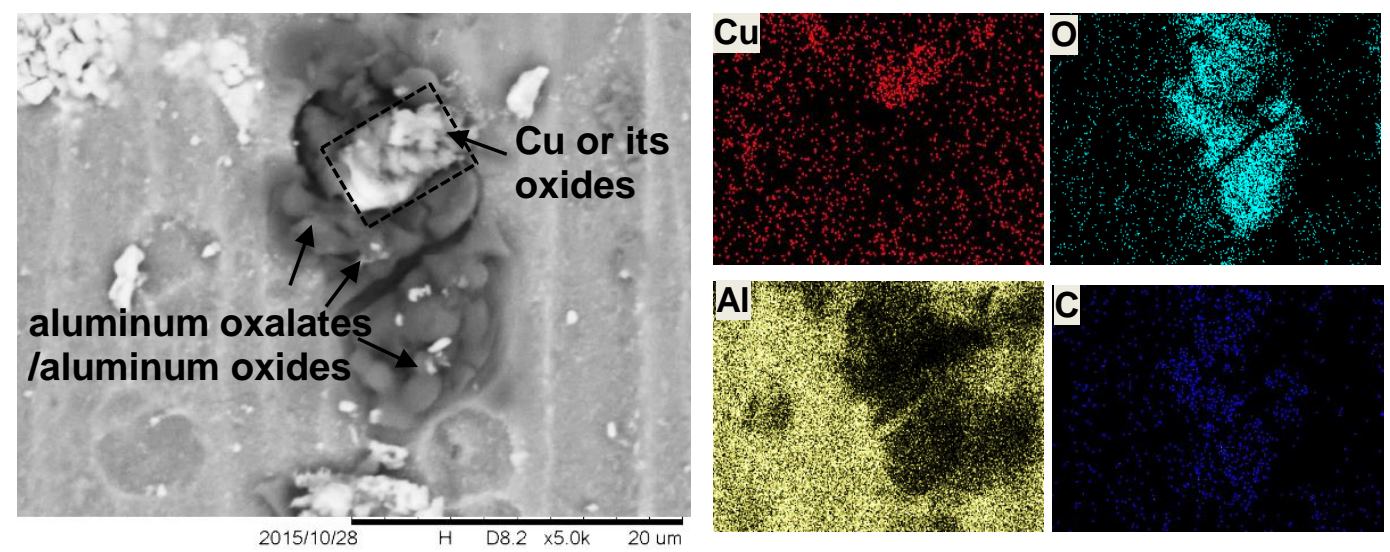

Fig. 9 
Table 1.

\begin{tabular}{|c|c|}
\hline Sample & experimental procedures \\
\hline control & untreated coupons only exposed to the humid environment \\
\hline $\mathrm{NaCl}$ & $\begin{array}{l}\text { coupons immersed in sterile } 3.5 \mathrm{wt} \% \mathrm{NaCl} \text { solution for } \sim 30 \mathrm{~s} \text {, and then removed from } \\
\qquad \mathrm{NaCl} \text { solution and placed in the wells }\end{array}$ \\
\hline agar & untreated coupons placed on PDA surfaces \\
\hline $\mathrm{NaCl}+$ agar & $\begin{array}{l}\text { coupons immersed in sterile } 3.5 \mathrm{wt} \% \mathrm{NaCl} \text { solution for } \sim 30 \mathrm{~s} \text {, and then removed from } \\
\qquad \mathrm{NaCl} \text { solution and placed on PDA }\end{array}$ \\
\hline A. niger & coupons placed on PDA and inoculated with spore suspension \\
\hline $\mathrm{NaCl}+A \cdot$ niger & $\begin{array}{l}\text { coupons immersed in sterile } 3.5 \mathrm{wt} \% \mathrm{NaCl} \text { solution for } ~ 30 \mathrm{~s} \text { prior, and then removed } \\
\text { from } \mathrm{NaCl} \text { solution and placed on PDA and inoculated with spore suspension }\end{array}$ \\
\hline
\end{tabular}

Note: Each coupon was placed inside a well of a six-well plate, which was enclosed with the lid. 


\section{Graphical abstract}

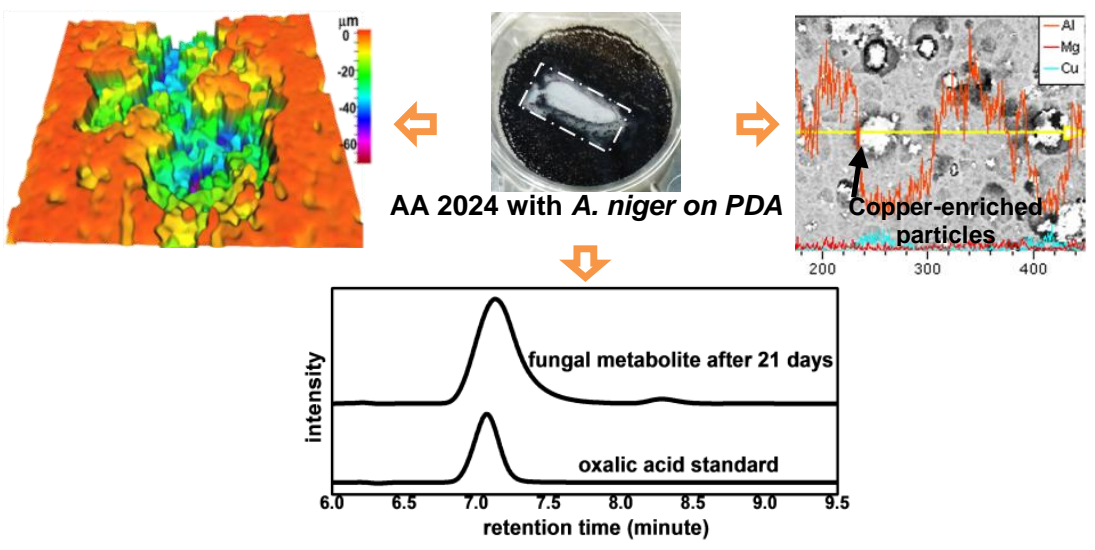

